\title{
Motion Type Verification Studies Using Accelerometer Sensor Data With Local Mean Decomposition
}

\author{
${ }^{1}$ Mustafa Yasin Esas and ${ }^{1}$ Fatma Latifoğlu \\ ${ }^{1}$ Faculty of Engineering, Department of Biomedical Engineering Erciyes University, Turkey
}

\begin{abstract}
It is a significant improvement that the physical movements directly related to human physiology can be detected with high accuracy using sensors. In our study, three-axis accelerometer data recorded using a cell phone sensor in a controlled manner were used. Validation of walking, jogging, up-stairs, down-stair movements is aimed. For this purpose, local mean decomposition (LMD) function was used. The axis $(\mathrm{x}, \mathrm{y}, \mathrm{z})$ in which the orthogonality value obtained from LMD was high was determined. Then, it was evaluated that there is movement in the direction of high value axis. While there is a high degree of accuracy in up-stair, down-stair and jogging movements, the desired success in walking movement was not achieved.
\end{abstract}

Key words: accelerometer, local mean decomposition, sensor, motion

\section{Özet}

İnsan fizyolojisine doğrudan bağlı olan fiziksel hareketlerin, sensörler kullanılarak yüksek doğrulukta tespit edilebilmesi önemli bir gelişmedir. Çalışmamızda, kontrollü bir şekilde bir cep telefonu sensörü kullanılarak kaydedilen üç eksenli ivmeölçer verileri kullanılmıştır. Yürüme, koşu, merdiven çıkma ve merdiven inme hareketlerinin doğrulanması amaçlanmaktadır. Bu amaçla, yerel ortalama ayrışımı (LMD) fonksiyonu kullanılmıştır. LMD' den elde edilen ortagonallik değerinin yüksek olduğu eksen $(\mathrm{x}, \mathrm{y}, \mathrm{z})$ belirlenmiştir. Daha sonra, yüksek ortagonallik değerine sahip eksen doğrultusunda hareket olduğu yönünde değerlendirme yapılmıştır. Merdiven çıkma, merdiven inme ve koşu hareketlerinde ortagonallik değerine bağlı olarak sensör bilgisinden hareket türü tespitinde yüksek derecede doğruluk elde edilirken, yürüme hareketinde istenen başarıya ulaşılamamıştır.

Anahtar kelimeler: ivmeölçer, yerel ortalama ayrışımı, sensör, hareket

\section{Giriş}

Günümüzde hareket verilerinin kaydı akıllı telefonlar, özellikle veri kaydı için geliştirilmiş sensörler ve çeşitli tipte elektronik cihazlar ile gerçekleştirilmektedir. Genellikle cihazlar içerisinde bulunan ivme ölçer, jiroskop ve manyetometre sensörleri aracılığıyla hareket veri kayıtları gerçekleştirilmektedir. Çalışmamızda ivme ölçer sensörü kaydına ilişkin veriler kullanılmıştır. Veriler M. Malekzadeh ve arkadaşlarının [1] yaptığı çalışma neticesinde çeşitli boy, kilo, yaş ve cinsiyet bilgisine sahip 24 kişiden alınmıştır. Çalışmamızda ise 5 erkek ve 5 kadın bireye ait ivme ölçer verileri kullanılmıştır. Veriler kontrollü bir biçimde Iphone 6s telefonun kişilerin pantolon ceplerine konulması ve belirlenen hareketleri yapması sonucu kaydedilmiştir. Çalışmamızda koşma, yürüme, merdiven inme ve merdiven çıkma hareketlerine

*Corresponding author: Address: Faculty of Engineering, Department of Biomedical Engineering Erciyes University, Kayseri TURKEY. E-mail address: mustafaesas@gmail.com 
ait veriler değerlendirilmiştir. Çalışmamızda kullanılan ivme ölçer veri kayıtları 3 eksenden (x, y, z) oluşmaktadır. Böylece yatay ve dikey düzlemlerdeki hareket bilgisi tespit edilebilmektedir. Elde edilen herbir eksendeki veriye yerel ortalama ayrışımı (LMD) [2] fonksiyonu uygulanmıştır. LMD den elde edilen ortagonallik bilgisine dayalı olarak hangi eksendeki hareket değişiminin daha fazla olduğu tespit edilmiş ve LMD ye dayalı olarak hareket bilgisi doğrulanmıştır.

\subsection{Yerel Ortalama Ayrışımı (LMD)}

Fourier dönüşümü, zaman bölgesi ve frekans bölgesi analizinde bir sinyal köprüsü oluşturmuştur. Ancak Fourier analizi bir sinyalin hangi zamanda hangi frekans bilgisine sahip olduğunu tespit edemez. Bu nedenle, Fourier analizi durağan olmayan sinyaller için geçerli değildir. Zaman frekans analizi yöntemlerinin çoğu son zamanlarda önerilmiş, yerel dalga ayrıştırma yöntemine daha fazla dikkat edilmiştir. Ampirik mod ayrışması (EMD) gibi, LMD de S. S. Jonathan [2] tarafindan önerilen doğrusal olmayan ve sabit olmayan sinyal için bir sinyal işleme yöntemidir. Dalgacık dönüşümü ile karşılaştırıldığında, LMD, sinyali, uyarlanabilir bir ayrıştırma yöntemi olan, temel fonksiyonu olmayan bir şekilde ayrıştırır [3]. LMD, konuşma sinyali işleme, hata tespiti ve tıbbi sinyal işleme gibi birçok mühendislik alanında yaygın olarak kullanılmasına rağmen, teorik temeli ve kapsamının muhakemesinde hala boşluklar var denilebilir [4]. LMD, sinyalin [5] ayrıştırılması sürecinde son nokta etkisi ve mod karıştırma problemine sahiptir. Mod karıştırma işleminin özü, LMD' nin birbirleriyle karş1lıklı eşleşmesiyle elde edilen ürün fonksiyonlarının bilgisidir. $\mathrm{Bu}$ ürün fonksiyonlarının eksik ortogonal olmasıdır. Bir veri kümesine LMD uygulanması sonucu elde edilen ortagonallik değeri veri setinin içinde ne kadar değişim olduğuna ilişkin bilgi taşıyabilmektedir. Bu kapsamda çalışmamızda ivme ölçer veri kayıtlarının her bir eksenden elde edilen verisine LMD uygulanmış ve ortagonallik değerleri karşılaştırılmıştır [6].

\subsection{Literatür Bilgisi}

Hareket analizi için yapılan mezvut çalışmalar üzerine literatür taraması yapılmıştır. 2018 yılında yayınlanmış bir derleme makalede 61 makale üzerinde yapılımış çalışmalar incelenmiştir. Hareket sensörleri kullanılarak yapılan çalışmalarda, bir fiziksel hareketin farklı vücut ölçülerine sahip insanlarda benzer sensör çıktıları verebildiği vücut bölgesinin bel bölgesi olduğu tespit edilmiştir [7].

Çocuklarda hareket verilerinin kaydedildiği bir çalışma incelenmiştir. Bu çalışmada çocuklardan ivmeölçer sensörü ile kayıtlar alınmış, alınan kayıtlarda da sadece adım sayısı ve aktivite enerji harcaması hesabı yapılmıştır [8].

Timo Sztyler ve arkadaşları giyilebilir cihazlarla pozisyona bağlı aktivite tanıma üzerine çalışma yapmışlardır. Bu çalışmada, ivme ölçer verilerine dayanan konuya özel ve çapraz konulara yönelik aktivite tanıma yaklaşımlarına ilişkin kapsamlı deneyler ile giyilebilir cihazın vücuttaki pozisyonunu tanıma sorununa odaklanılmıştır. Bu bağlamda, 15 katılımcıdan, farklı vücut pozisyonlarında 7 giyilebilir cihaz taşıdıkları 8 ortak etkinlik için toplanan gerçek bir veri seti 
sunulmuştur. Sonuçlar, cihaz konumunun tespit edilmesinin, ortak aktiviteler için aktivite tanıma sonucunu sürekli olarak iyileştirdiğini göstermektedir. Çapraz konular modellerinde, belde, birkaç kişi için aynı aktivite için hızlanma modellerinin en benzer olduğu en uygun cihaz yeri olarak tanımlanmıştır. Bu bağlamda, sonuçlar, çapraz konulara dayalı modellerin fiziksel özelliklerinin güvenilirliği için kanıt sağlamaktadır [9].

Hareket verileri üzerine literatürde yapılmış bir çok çalışma bulunmaktadır. Hareket tespiti üzerine çeşitli çalışmalar yapılmıştır. Bu çalışmalarda ortak olarak tespit edilen durum çeşitli fizyolojik özelliklere sahip bireylerde bel bölgesinden alınan hareket verilerine ait kayıtların uyumlu çıktılar verdiğidir. Bizim çalışmamızın özgün tarafı ise hareket tespitinin farklı bir yol olarak LMD fonksiyonu kullanılarak ortagonallik aracılığıyla elde edilmesi üzerinedir.

\section{Materyal ve Yöntem}

Çalışmamızda kullanılan veriler daha önce kontrollü bir şekilde kaydedilip sonra konu ile ilgili akademik çalışmaların yapıldığı test edilmiş güvenilir bir veridir [1]. 3 eksen ivme ölçer verisi kullanılmıştır. Veriler $50 \mathrm{~Hz}$ örnekleme frekansına sahiptir. Her bir verinin aynı uzunlukta olmasına dikkat edilmiştir. Bu nedenle en kısa veri kaydı olan 14 sn. lik veriye dayalı olarak çalışmaya dahil edilen tüm kayıtların ilk 14 saniyesi kullanılmıştır. 5 kadın, 5 erkek katılımcı olmak üzere toplam 10 kişiye ait kayıtlar analiz edilmiştir.

- Veriler düzenlendikten sonra her bir kişiye ait koşma, yürüme, merdiven çıkma ve merdiven inme aktivitelerine ait kayıtlar MATLAB ortamına yüklenmiştir.

- Daha sonra tüm kayıtlara LMD fonksiyonu uygulanarak ortagonellik değerleri elde edilmiştir.

- Ortagonallik değerleri herbir x, y, z ekseni için tüm hareket sınıflarında (koşma, yürüme, merdiven ç1kma ve inme) tüm bireylerde tespit edilmiştir.

- Son olarak elde edilen ortagonallik değerlerine dayalı olarak hareket sınıfının belirlenmesindeki başarı oranları ortaya konulmuştur.

\section{Bulgular}

Aşağıdaki tablolarda koşma, yürüme, merdiven inme ve merdiven çıkma aktiviteleri sonucu kayıt edilen ivmeölçer verilerinin $\mathrm{x}, \mathrm{y}, \mathrm{z}$ eksenlerine ait verilerine uygulanan LMD çalışması sonucu elde edilen ortagonellik değerleri görülmektedir. Koşma ve yürüme aktiviteleri sırasında x ve $\mathrm{y}$ eksenleri doğrultusunda hareket değişimleri olacağından, $\mathrm{x}$ ve y eksenlerine ait ortagonallik değerlerinin $\mathrm{z}$ eksenine ait değerden daha yüksek olması beklenmektedir. Merdiven inme ve çıkma aktiviteleri sırasında ise $\mathrm{z}$ ekseni doğrultusunda hareket değişiminin $\mathrm{x}$ ve $\mathrm{y}$ eksenleri doğrultusundaki hareket değişimlerinden daha fazla olması beklendiğinden $\mathrm{z}$ eksenine ait ortagonellik değerinin daha yüksek olması beklenmektedir. 
Tablo 1. Merdiven İnme Aktivitesi Ortagonallik Değerleri

\begin{tabular}{ccccc}
\hline MERDiVEN INME & $\mathbf{x}$ & $\mathbf{y}$ & \multicolumn{1}{c}{$\mathbf{z}$} & $\mathbf{e} / \mathbf{k}$ \\
\hline $\mathbf{1}$ & 0,0479 & 0,0393 & 0,0959 & $\mathrm{e}$ \\
$\mathbf{2}$ & 0,0806 & 0,0372 & 0,1258 & $\mathrm{k}$ \\
$\mathbf{3}$ & 0,0554 & 0,1131 & 0,0642 & $\mathrm{e}$ \\
$\mathbf{4}$ & 0,0698 & 0,0568 & 0,1257 & $\mathrm{k}$ \\
$\mathbf{5}$ & 0,0496 & 0,0622 & 0,0933 & $\mathrm{k}$ \\
$\mathbf{6}$ & 0,0345 & 0,0947 & 0,0664 & $\mathrm{e}$ \\
$\mathbf{7}$ & 0,1594 & 0,0975 & 0,0361 & $\mathrm{k}$ \\
$\mathbf{8}$ & 0,0646 & 0,0675 & 0,0921 & $\mathrm{k}$ \\
$\mathbf{9}$ & 0,0336 & 0,0768 & 0,0543 & $\mathrm{e}$ \\
$\mathbf{1 0}$ & 0,0914 & 0,139 & 0,0597 & $\mathrm{e}$ \\
\hline Ortalama & $\mathbf{0 , 0 6 8 6 8}$ & $\mathbf{0 , 0 7 8 4 1}$ & $\mathbf{0 , 0 8 1 3 5}$ & \\
\hline
\end{tabular}

Tablo 1 den görüldüğü üzere merdiven inme aktivitesi sırasında $\mathrm{z}$ eksenine ait ortalama ortagonallik değerinin x ve y eksenlerine göre daha yüksek olduğu görülmektedir.

Tablo 2. Merdiven Çıkma Aktivitesi Ortagonallik Değerleri

\begin{tabular}{clcll}
\hline $\begin{array}{c}\text { MERDIVEN } \\
\text { ÇIKMA }\end{array}$ & \multicolumn{1}{c}{$\mathbf{x}$} & $\mathbf{y}$ & \multicolumn{1}{c}{$\mathbf{z}$} & $\mathbf{e} / \mathbf{k}$ \\
\hline $\mathbf{1}$ & 0,0492 & 0,0713 & 0,1098 & $\mathrm{e}$ \\
$\mathbf{2}$ & 0,0696 & 0,0366 & 0,1505 & $\mathrm{k}$ \\
$\mathbf{3}$ & 0,0577 & 0,0775 & 0,1218 & $\mathrm{e}$ \\
$\mathbf{4}$ & 0,0711 & 0,0426 & 0,1253 & $\mathrm{k}$ \\
$\mathbf{5}$ & 0,025 & 0,0401 & 0,1444 & $\mathrm{k}$ \\
$\mathbf{6}$ & 0,0575 & 0,0567 & 0,0562 & $\mathrm{e}$ \\
$\mathbf{7}$ & 0,1596 & 0,0427 & 0,096 & $\mathrm{k}$ \\
$\mathbf{8}$ & 0,1024 & 0,0376 & 0,1551 & $\mathrm{k}$ \\
$\mathbf{9}$ & 0,0404 & 0,1405 & 0,1783 & $\mathrm{e}$ \\
$\mathbf{1 0}$ & 0,071 & 0,1004 & 0,1419 & $\mathrm{e}$ \\
\hline Ortalama & $\mathbf{0 , 0 7 0 3 5}$ & $\mathbf{0 , 0 6 4 6}$ & $\mathbf{0 , 1 2 7 9 3}$ & \\
\hline
\end{tabular}

Tablo 2 den görüldüğü üzere merdiven çıkma aktivitesi sırasında z eksenine ait ortalama ortagonallik değerinin $\mathrm{x}$ ve y eksenlerine göre daha yüksek olduğu görülmektedir. 
Tablo 3. Koşu Aktivitesi Ortagonallik Değerleri

\begin{tabular}{cllll}
\hline KOŞU & \multicolumn{1}{c}{$\mathbf{x}$} & \multicolumn{1}{c}{$\mathbf{y}$} & \multicolumn{1}{c}{$\mathbf{z}$} & $\mathbf{e} / \mathbf{k}$ \\
\hline $\mathbf{1}$ & 0,1256 & 0,0674 & 0,0415 & $\mathrm{e}$ \\
$\mathbf{2}$ & 0,1195 & 0,243 & 0,0809 & $\mathrm{k}$ \\
$\mathbf{3}$ & 0,0606 & 0,1874 & 0,0912 & $\mathrm{e}$ \\
$\mathbf{4}$ & 0,0609 & 0,123 & 0,0924 & $\mathrm{k}$ \\
$\mathbf{5}$ & 0,088 & 0,109 & 0,1091 & $\mathrm{k}$ \\
$\mathbf{6}$ & 0,0548 & 0,1417 & 0,0543 & $\mathrm{e}$ \\
$\mathbf{7}$ & 0,2711 & 0,0748 & 0,1041 & $\mathrm{k}$ \\
$\mathbf{8}$ & 0,0324 & 0,2242 & 0,0617 & $\mathrm{k}$ \\
$\mathbf{9}$ & 0,0332 & 2,6664 & 0,0295 & $\mathrm{e}$ \\
$\mathbf{1 0}$ & 0,0477 & 0,0704 & 0,0465 & $\mathrm{e}$ \\
\hline Ortalama & $\mathbf{0 , 0 8 9 3 8}$ & $\mathbf{0 , 3 9 0 7 3}$ & $\mathbf{0 , 0 7 1 1 2}$ & \\
\hline \multicolumn{6}{l}{}
\end{tabular}

Tablo 3 den görüldüğü üzere koşma aktivitesi sırasında y eksenine ait ortalama ortagonallik değerinin $\mathrm{x}$ ve $\mathrm{z}$ eksenlerine göre daha yüksek olduğu görülmektedir.

Tablo 4. Yürüme Aktivitesi Ortagonallik Değerleri

\begin{tabular}{cllll}
\hline YÜRய̈ME & \multicolumn{1}{c}{$\mathbf{x}$} & \multicolumn{1}{c}{$\mathbf{y}$} & \multicolumn{1}{c}{$\mathbf{z}$} & $\mathbf{e} / \mathbf{k}$ \\
\hline $\mathbf{1}$ & 0,1016 & 0,0525 & 0,201 & $\mathrm{e}$ \\
$\mathbf{2}$ & 0,1075 & 0,0406 & 0,1125 & $\mathrm{k}$ \\
$\mathbf{3}$ & 0,0775 & 0,0788 & 0,0949 & $\mathrm{e}$ \\
$\mathbf{4}$ & 0,0993 & 0,0686 & 0,1517 & $\mathrm{k}$ \\
$\mathbf{5}$ & 0,0502 & 0,0371 & 0,1466 & $\mathrm{k}$ \\
$\mathbf{6}$ & 0,0349 & 0,1244 & 0,0797 & $\mathrm{e}$ \\
$\mathbf{7}$ & 0,2907 & 0,0558 & 0,2222 & $\mathrm{k}$ \\
$\mathbf{8}$ & 0,0221 & 0,0369 & 0,09 & $\mathrm{k}$ \\
$\mathbf{9}$ & 0,1312 & 0,1184 & 0,0634 & $\mathrm{e}$ \\
$\mathbf{1 0}$ & 0,246 & 0,0818 & 0,0561 & $\mathrm{e}$ \\
\hline Ortalama & $\mathbf{0 , 1 1 6 1}$ & $\mathbf{0 , 0 6 9 4 9}$ & $\mathbf{0 , 1 2 1 8 1}$ & \\
\hline
\end{tabular}

Tablo 4 den görüldüğü üzere yürüme aktivitesi sırasında z eksenine ait ortalama ortagonallik değerinin $\mathrm{x}$ ve y eksenlerine göre daha yüksek olduğu görülmektedir. 


\section{Tartışma}

Tablo 1, 2, 3 ve 4 den elde edilen veriler değerlendirildiğinde:

- Merdiven inme ve çıkma aktiviteleri sırasında z eksenine ait ivme ölçer verilerinden elde edilen ortagonallik değerinin işlevsel olarak hareketi tanımlayabildiği tespit edilmiştir.

- Koşma aktivitesinin belirgin bir şekilde y ekseni verisinde ortagonallik değeri verdiği görülmüştür.

- Yürüme aktivitesinden elde edilen $\mathrm{x}, \mathrm{y}, \mathrm{z}$ yönlerindeki ivme ölçer verilerinin ortagonallik değerleri hareketi ayırt etmeye yarayan anlamlı bir değer vermemiştir.

- Merdiven çıkma aktivitesinin merdiven inme aktivitesine göre $\mathrm{z}$ ekseni verisinde daha yüksek miktarda ortagonallik değeri verdiği tespit edilmiştir.

- Çalışmada LMD fonksiyonu uygulanarak hareket tipinin doğrulanması çalışması yapılmıştır. LMD den elde edilen ortagonallik değerine göre merdiven inme, merdiven çıkma ve koşma aktiviteleri sırasında ivme ölçer sensöründe belirgin değişimler gözlemlenirken, yürüme aktivitesi sırasında daha küçük değişimler gözlendiği söylenebilir.

- LMD ye dayalı olarak koşma, merdiven inme ve çıkma aktiviteleri doğrulanabilirken, yürüme aktivitesi doğrulanamamıştır.

- Merdiven inme ve çıkma aktivitesi doğrulanmıştır. Ancak merdiven inme ve çıkma kendi içerisinde ayırt edilememiştir.

- Sadece ivme ölçer verisi hareket tespiti için yetersiz kalmaktadır.

- LMD' nin ivme ölçer verisine uygulanması başarılı sonuçlar vermekte ancak tek başına ivme ölçer verisi ile LMD yetersiz kalmaktadır.

\section{Sonuçlar}

Çalışmamızda ivme ölçer verisi kullanılmıştır. Sadece ivme ölçer verisine dayalı olarak, kullanılan yöntem ile hareketin tamamen tespit edilebilmesi mümkün değildir. Ancak tespit edilmiş bir hareketin yüksek başarı oranıyla doğrulanabilmesi mümkündür. Çalışmamız ön çalışma niteliğinde olup, çeşitli sensör verileri ve çeşitli analiz yöntemleri ile geliştirilmesi planlanmaktadır. Çalışmamız LMD' nin uygulanması kapsamında hareket verilerinin analizine yeni bir bakış açısı getirmekte olup literatüre katkı sağlayacak tespitler içermektedir. 


\section{Referanslar}

[1] Malekzadeh M, Clegg RG, Cavallaro A, Haddadi H. Mobile sensor data anonymization. In Proceedings of the International Conference on Internet of Things Design and Implementation (IoTDI '19) 2019. ACM, New York, NY, USA, 49-58. DOI: https://doi.org/10.1145/3302505.3310068

[2] Smith J S. The local mean decomposition and its application to EEG perception data [J]. JR Soc Interface, 2005; 2(5): 443-454.

[3] W. Sun, B. S. Xiong, J. P. Huang, et al. Fault diagnosis of a rolling bearing using wavelet packet de-nosing and LMD [J]. Journal of Vibration and Shock, 2012, 31(18): 153-156.

[4] L. Li, Y. X. Zhang, T. F. Ming. An improved LMD algorithm and its application in bearing fault diagnosis [J]. Journal of Vibration and Shock, 2016, 35(8): 183-186.

[5] H. J. Song, C. J. Huang, H. C. Liu. A new power quality disturbance detection method based on the improved LMD [J]. Proceedings of CSEE, 2014, 34(10): 1700-1708.

[6] Y. Xiao and Y. Dong, Local mean decomposition algorithm improved by de-correlation, (CISP-BMEI), Datong, 2016;1206-1210. doi: 10.1109/CISP-BMEI.2016.7852898

[7] Benson, L.C., Clermont, C.A., Bošnjak, E., Ferber, R., The use of wearable devices for walking and running gait analysis outside of the lab: A systematic review, Gait \& Posture, 2018;63:124-138.

[8] Baerg, S., Cairney, J., Hay, J., "Rempel, L., Mahlberg, N., Faught, B.E. Evaluating physical activity using accelerometry in children at risk of developmental coordination disorder in the presence of attention deficit hyperactivity disorder", Research in Developmental Disabilities 2011;32,1343-1350.

[9] Sztyler, T., Stuckenschmidt, H., Petrich, W., Position-aware activity recognition with wearable devices, Pervasive and Mobile Computing 2017;38:281-295. 